\title{
Optimization of Coagulation Process for Landfill Leachate Pre-Treatment Using Response Surface Methodology (RSM)
}

\author{
Talebi Amir \\ School of Industrial technology, Environmental Division, Universiti Sains Malaysia \\ 11800 Penang, Malaysia \\ E-mail: amirtalebi79@yahoo.com \\ Norli Ismail \\ School of Industrial technology, Environmental Division, Universiti Sains Malaysia \\ 11800 Penang, Malaysia \\ Phone: 60-4-653-2824, Fax: 60-4-657-3678Ｅ-mail: norlii@usm.my \\ Abbas F. M. Alkarkhi (Corresponding author) \\ School of Industrial technology, Environmental Division, Universiti Sains Malaysia \\ 11800 Penang, Malaysia \\ Phone: 60-4-653-2107, Fax: 60-4-657-3678Ｅ-mail: abbas@usm.my \\ Teng, T.T \\ School of Industrial technology, Environmental Division, Universiti Sains Malaysia \\ 11800 Penang, Malaysia \\ Tel: 60-4-653-2215, Fax: 60-4-657-3678 E-mail: ttteng@usm.my
}

\begin{abstract}
The effect of a coagulation process with ferrous sulfate as a coagulant on COD, apparent color and turbidity was evaluated using response surface methodology (RSM). A jar test method was used for the pre-treatment of mature landfill leachate of the Pulau Burung Sanitary Landfill, Malaysia. The results of response surface methodology (RSM) showed that ferrous sulfate was most efficient under alkaline conditions and with a coagulant dosage $10 \mathrm{~g} / \mathrm{l}$. At the optimum setting for coagulant dosage was $10 \mathrm{~g} / 1$ and $\mathrm{pH} 11.7$, resulted in maximum of (22\%) in COD, (42\%) in apparent color, and $(31 \%)$ in turbidity. It was observed that the COD, apparent color and turbidity reductions decreased with $\mathrm{pH}$ and $\mathrm{FeSO}_{4}$ levels beyond the optimum conditions. This paper illustrates the usefulness of experimental design in running experiments and optimization.
\end{abstract}

Keywords: Leachate, Response Surface Methodology (RSM), Coagulation, Ferrous Sulphate, Central Composite Design (CCD)

\section{Introduction}

A widely used method for treating municipal solid waste (MSW) is disposal landfill. Up to $95 \%$ of the MSW collected worldwide is disposed of in landfills (Fadel et al., 1997).

In a landfill, solid waste undergoes physico-chemical and biological changes. Degradation of the organic fraction of the wastes in combination with percolating rainwater produces a highly contaminated liquid called "leachate" (Kurniawan et al., 2006/a), which often is the most important point source of organic ground water contamination. Leachate from municipal, chemical or sanitary landfills are amongst the most contaminated polluted waters known (Oppenlander, 2003). Over 200 individual organic compounds have been identified in leachate, including cyclic and bicyclic compounds and aromatic hydrocarbons, at concentrations from $<1 \mu \mathrm{g} / \mathrm{l}$ to several hundred $\mu \mathrm{g} / 1$ (Paxeus, 2000). The type of leachate depends on factors such as age and type of landfill, $\mathrm{pH}$, and $\mathrm{BOD}_{5} / \mathrm{COD}$ ratio. Leachate may be classified as young (or raw), and stabilized (mature). 
To remove or reduce refractory pollutants in landfill leachate, several types of treatment have been adopted. Biological processes are the most cost-effective, but are not sufficiently effective if used as the sole treatment. Pre-treatment methods, usually physico-chemical processes, have been used to enhance leachate biodegradability $\left(\mathrm{BOD}_{5} / \mathrm{COD}\right.$ ratio). These physico-chemical treatments include ammonium stripping, chemical precipitation, coagulation-flocculation, ultrafiltration (UF), nanofiltration (NF) and reverse osmosis (RO) (Kurniawan et al., 2006/b). Amongst these methods, coagulation-flocculation often is favored because it is cost effective, and easily accessible. Many researchers have studied landfill leachate treatment with various coagulants and objectives. A study found 55\% and $42 \% \mathrm{COD}$ reduction with $\mathrm{FeCl}_{3}$ and $\mathrm{Al}_{2}\left(\mathrm{SO}_{4}\right)_{3}$ as a coagulant, respectively (Amokrane et al., 1997). Another study found 50-70 \% color removal by combining activated carbon and coagulation (Zamora et al., 2000). A combination of coagulation and Fenton oxidation with $\mathrm{FeCl}_{3}$ as a coagulant reduced COD by up to $90 \%$ (US Environmental Protection Agency, 2002). In another study coagulation pre-treatment by $\mathrm{FeCl}_{3}$ effectively removed various large molecules from the raw leachate and aided subsequent treatment processes (Wu et al., 2004).

The objectives of this study were to evaluate the efficiency of ferrous sulfate $\left(\mathrm{FeSO}_{4}\right)$ as a coagulant on leachate generated from Pulau Burung Landfill Site (PBLS) located in Penang, Malaysia. Amongst the various coagulants, ferrous sulfate had been less under consideration in comparison with popular coagulants such as ferric chloride $\left(\mathrm{FeCl}_{3}\right)$ and aluminum sulfate $\left(\mathrm{Al}_{2}\left(\mathrm{SO}_{4}\right)_{3}\right)$;. The reduction of $\mathrm{COD}$, apparent color and turbidity were the objectives of the study.

\section{Materials and methods}

\subsection{Sampling}

Samples of leachate were collected from the Pulau Burung sanitary landfill which is located in the Penang state of Malaysia and is classified as a semi-aerobic landfill site. This landfill receives an average of 500,000 metric tons of municipal solid waste annually and is equipped with two leachate storage ponds and aeration systems that facilitate further treatment processes. Samples were taken in September 2007 from pond LP1 and kept in plastic containers (high density polyethylene HDPE-volume of 40 litres), then transferred to the laboratory and held at $4^{\circ} \mathrm{C}$ until used. Leachate was characterized for $\mathrm{pH}, \mathrm{COD}, \mathrm{BOD}_{5}$, apparent color and turbidity. Analytical procedures of APHA (Standard method for examination of water and wastewater, 1992) and HACH standard methods (modification of APHA standard method as approved by United State Environmental Protection Agency (USEPA)) were followed.

The leachate obtained was classified as stabilized type based on leachate characterization.

\subsection{Apparatuses}

Apparent color and COD were measured by a HACH DR/120 portable datalogging spectrophotometer, (reported in units of $\mathrm{Pt} / \mathrm{Co}$ and mg/l, programs 120 and 435, respectively). Apparent color units were calibrated based on the APHA recommended standard of 1 color unit being equal to $1 \mathrm{mg} / \mathrm{l}$ platinum as chloroplatinate ion (HACH Water Analysis Handbook, 1997). COD was measured with Dichromate Reactor Design, colorimetric, USEPA approved. BOD $_{5}$ was measured according to the standard method for examination of water and wastewater (reported in $\mathrm{mg} / \mathrm{l}$ ) with an YSI 5100 dissolved oxygen meter. $\mathrm{pH}$ was measured by $\mathrm{HACH}$ to adjust with a Senion $\mathrm{pH}$ meter with sulfuric acid (concentrated $\mathrm{H}_{2} \mathrm{SO}_{4}$ ) and sodium hydroxide $(\mathrm{NaOH}-10 \mathrm{M}$ ) was used for $\mathrm{pH}$ setup during experiments. Turbidity was measured with a HACH 2100 turbiditimeter (reported in NTU: Nefephelometric Turbidity Unit). $\mathrm{FeSO}_{4} \cdot 6 \mathrm{H}_{2} \mathrm{O}$ supplied by Bedizen chemicals was used as coagulant.

Preliminary experiments were run using Jar test method, varying the coagulant dosage at an arbitrary dosage, and then varying the $\mathrm{pH}$ at the fixed coagulant dosage, in which the highest responses removals were achieved.

\subsection{Experimental Design}

Researchers in the field of engineering and technology often wish to determine the values of the process input parameters at which the responses reach their optimum. The optimum could be either a maximum or a minimum of a particular function in terms of the process input parameters. RSM is one of the optimization tools currently in widespread use in describing the performance of the coagulation process and to find the optimum of the responses of interest.

RSM is a set of mathematical and statistical tools that is useful for modeling and predicting the response of interest affected by a number of input variables with the aim of optimizing this response (Montgomery, 2004). RSM also specifies the relationships among one or more measured responses and the essential controllable input factors (Khuri and Cornell, 1996). When all independent variables are measurable, controllable and continuous in the experiments, with negligible error, the response surface can be expressed as:

$$
y=f\left(x_{1}, x_{2}, \ldots, x_{k}\right)
$$


where $\mathrm{k}$ is the number of independent variables. To optimize the response " $\mathrm{y}$ ", it is necessary to approximate the functional relationship between the independent variables and the response surface. Usually a second-order polynomial Eq. (2) is used in RSM:

$$
y=\beta_{0}+\sum_{i=1}^{2} \beta_{i} x_{i}+\sum_{i=1}^{2} \beta_{i i} x_{i}^{2}+\sum \sum_{i<j} \beta_{i j} x_{i} x_{j}
$$

Where $\beta_{0}, \beta_{i}, \beta_{i i}$, and $\beta_{i j}$ are regression coefficients, and $x_{i}$ are the coded variables. The relationship between the natural variable $\xi_{i}$ and the coded variables $x_{i}$ is

$$
x_{i}=\frac{\xi_{i}-(\text { High level }+ \text { Low level }) / 2}{(\text { High level }- \text { Low level }) / 2}
$$

\section{Results and Discussion}

A central composite design (CCD) (Montgomery, 2004; Khuri and Cornell, 1996) with two indepent variables wąs used. Thirteen runs were required to cover all possible combinations of factor levels. Data were collected as a $2^{2}$ factorial design augmented by five (5) center points and four extra points (axial points or star points; Table1). The experiments were run in random order to minimize the effects of unexpected variability in the observed responses.

The experimental range for each independant variable was based on preliminary trials, coagulant dosage level were ( 8-10 g/l) and $\mathrm{pH}$ levels were (10-12).

The results of a 13-run CCD with two variables, coagulant dosage and $\mathrm{pH}$, and three responses, COD, apparent color, and turbidity reductions, are given in Table 1 . The percentage of COD, apparent color, and turbidity reductions were studied in their specified levels, coagulant Dosage (8-10 g/l) and $\mathrm{pH}(10-12)$. Response surface methodology was used to evaluate the effect of coagulant dosage and $\mathrm{pH}$ on the COD, apparent color, and turbidity reductions. Then a model that describes the behavior of each response in order to optimize the process by finding the best setting of coagulant dosage and $\mathrm{pH}$ that maximize COD, apparent color, and turbidity reductions was built. Second-order models for COD reduction, apparent color removal and turbidity reductions in terms of coded variable are given by Eq. 3, Eq.4, and Eq.5, respectively:

$$
\begin{aligned}
& y_{1}=17.68+1.71 x_{1}+4.6 x_{2}-0.62 x_{1}^{2}-1.82 x_{2}^{2}+0.58 x_{1} x_{2} \\
& y_{2}=31.34+7.46 x_{1}+221.60 x_{2}+0.82 x_{1}^{2}-12.95 x_{2}^{2}-9.43 x_{1} x_{2} \\
& y_{3}=3.38+3.94 x_{1}+47.13 x_{2}-.53 x_{1}^{2}-33.65 x_{2}^{2}+22.13 x_{1} x_{2}
\end{aligned}
$$

where $\mathrm{x}_{1}$ and $\mathrm{x}_{2}$ reperesent the coagulant dosage and $\mathrm{pH}$, respestively, and $\mathrm{y}_{1}, \mathrm{y}_{2}$ and $\mathrm{y}_{3}$ reperesent the responses COD, color and turbidity reductions, respectively.

The second-order regression models obtained for COD, apparent color, and turbidity reductions are satisfactory since the value of the coefficient of determination $\left(R^{2}\right)$ is high and close to 1 . The values of $R^{2}$ for COD, apparent color and turbidity reduction models are $0.93,0.92$ and 0.99 , respectively. This indicates that 0.95 to 0.98 of the total variation is explained by the model and only $(0.01-0.07)$ of the total variation is unexplained.

The results of analysis of variance (ANOVA) for the quadratic models summarize the analysis of each response and show the significant model terms. Table 2, shows the ANOVA for COD, apparent color, and turbidity reductions. The analysis of variance reveals that a second-order model adequately fits the experimental data for all responses. For COD reduction, It can be seen that linear effects of coagulant dosage $\left(x_{1}\right)$ and $\mathrm{pH}\left(x_{2}\right)$ are significant. The quadratic contribution of coagulant dosage $\left(x_{1}^{2}\right)$ and the interaction term between coagulant dosage and $\mathrm{pH}\left(x_{1} x_{2}\right)$ does not have a significant effect on COD reduction although the quadratic contribution for $\mathrm{pH}\left(x_{2}^{2}\right)$ did. The linear and quadratic effects of $\mathrm{pH}$ and the linear effect of coagulant dosage on apparent color removal are significant, while the quadratic contribution of coagulant dosage is not. Interaction term was significant at less than $10 \%$. Interaction between $\mathrm{pH}$ and coagulant dosage could be due to the acidic character of the ferrous ion causing the $\mathrm{pH}$ to decrease following the addition of the coagulant. Thus, adding coagulant to the leachate precipitates iron as $\mathrm{Fe}(\mathrm{OH})_{2}$ and $\mathrm{Fe}(\mathrm{OH})$ 3 and decreases the $\mathrm{pH}$. This result is consistant with previous research in which at high $\mathrm{pH}$ values, the precipitation of metal-hydroxides occurs mainly through co-precipitation (Tatsi et al., 2003). Another reason for the interaction between $\mathrm{pH}$ and coagulant dosage could be the presence of anionic surface agents in the leachate that have a negative charge at alkaline $\mathrm{pH}$. Thus, the polar head of the surface molecule enters the double layer and stabilizes the negative colloids (Eckenfelder, 2000). The results of ANOVA for turbidity reduction showed that the linear effect of coagulant dosage and $\mathrm{pH}$, quadratic effect over the linear effect of $\mathrm{pH}$, and interaction term all were significant, while the quadratic effect for coagulant dosage was insignificant. The relative contribution of each factor to each response (COD, apparent color, 
and turbidity reductions) was measured directly by the regression coefficient in the fitted model. A positive sign for the regression coefficient in the fitted model indicates the ability of the factor to increase the response, whilst the negative sign indicates the ability of a factor to decrease the response. The three-dimensional response surface for COD, apparent color and turbidity reductions are given in Figs. 1, 2, and 3, respectively, showing the effect of $\mathrm{pH}$ and coagulant dosage on COD, apparent color, and turbidity reductions. It can be seen that all responses exhibited a clear peak, which suggests that the optimum condition for maximum COD, apparent color and turbidity reductions are within the design boundary. Interaction plots between coagulant dosage and $\mathrm{pH}$ for $\mathrm{COD}$, apparent color, and turbidity are given in Figs. 4, 5, and 6, respectively. It is evident that COD is not affected by the interaction (Fig.4) and the factors work independently, while Figs. 5and 6 show that the interaction between coagulant dosage and $\mathrm{pH}$ affect apparent color and turbidity reductions which indicate that the difference in apparent color and turbidity reductions at different levels of $\mathrm{pH}$ is not the same at all levels of coagulant dosage, and vice versa. Thus, the difference in apparent color and turbidity results mainly due to the interaction between $\mathrm{pH}$ and coagulant dosage.

\section{Optimization of the experiment}

Basing on the factorial experiment results we ran an optimization study to identify the optimal operating conditions for coagulant dosage and $\mathrm{pH}$. In fact, once the models have been developed and checked for adequacy, the optimization criteria can be set to find out the optimum operating conditions. The maximum reduction for all responses was achieved at dosage $10 \mathrm{~g} / \mathrm{FeSO}_{4}$ and $\mathrm{pH}$ 11.7. To validate the optimum combination of the process variables, confirmatory experiments were carried out. The selected combinations of the two variables resulted in $21.54 \%$ COD reduction (influent: $3520 \mathrm{mg} / \mathrm{l}$, effluent: $2762 \mathrm{mg} / \mathrm{l}$ ), 41.84\% apparent color removal (influent: 6420 Pt.Co, effluent: 3734 Pt.Co), and $31.20 \%$ turbidity reduction (influent: 118 N.T.U, effluent: 81.2 N.T.U). it can be said that COD, apparent color and turbidity reductions all had the same behavior (Maximum reduction) in the optimum range and decreased beyond it. This behavior suggests that all of the responses were mostly produced by the organic matters as the same source. This pattern in consistent with that of Azizi et al. (2007) who stated that "color was mainly contributed by organic matters with some insoluble forms that exhibited turbidity and suspended solids readings".

\section{Conclusion}

Based on application of coagulation-flocculation with ferrous sulfate and anionic polymers, $\mathrm{w}$ concluded that the optimum conditions for $\mathrm{pH}$ and coagulant dosage are 11.7 and $10 \mathrm{~g} / \mathrm{l}$, respectively, resulted in $21.54 \%$ COD reduction (influent: $3520 \mathrm{mg} / 1$, effluent: $2762 \mathrm{mg} / \mathrm{l}$ ), 41.84\% apparent color removal (influent: 6420 Pt.Co, effluent: 3734 Pt.Co), and $31.20 \%$ turbidity reduction (influent: 118 N.T.U, effluent: 81.2 N.T.U). By adding coagulant to sample and after rapid mixing stage, the initial $\mathrm{pH}$ reduced, but still remained in alkaline range, suggesting that there was an effect of acidic characteristic of ferrous sulphate.

\section{Acknowledgement}

The study was funded through USM short term grant (grant number 304/PTEKIND/638090. The authors acknowledge the USM for providing all facilities.

\section{References}

Amokrane, A., Comel, C., Veron, J.. (1997). Landfill leachate treatment pretreatment by coagulation-flocculation, Water Res., 31, 2775-2782.

APHA Standard method for examination of water and wastewater, $18^{\text {th }}$ edition American Public Health Association, Washington, D.C. (1992).

Azizi, H. A., Alinas, S., Aldan, M. N. Farideh., Assari, A. H., Zahari, M. SH. (2007). color removal from landfill leachate by coagulation and flocculation process, Bioresource Technology 98 218-220.

Eckenfelder, W. W., Industrial water pollution control, McGraw-Hill Series in water resources and environmental engineering, $3^{\text {rd }}$ edition, U.S.A: (2000).

Fadel, M. EL., Findikakis, A. N., Leckie, J. O.. (1997). Environmental impacts of solid waste landfilling, J. Environ. Manage., 50, 1-25.

HACH Water Analysis Handbook (1997). $3^{\text {rd }}$ edition, U.S.A

Khuri AI, Cornell JA. Response surfaces design and analysis. 2nd edition. New York: Marcel Dekker; (1996).

Kurniawan, T., A., Lo, W., Chan, G., Y.. (2006/a) Physico-chemical treatment for removal of recalcitrant contaminants from landfill leachate, J. Hazard. Mater., B129, 80-100.

Kurniawan, T., A., Lo, W., Chan, G., Y.. (2006/b). Degradation of recalcitrant compounds from stabilized landfill leachate using a combination of ozone-GAC adsorption treatment, J. Hazard. Mater., B137, 443-455.

Montgomery DC. Design and analysis of experiments, 5th edition. New York: Wiley; (2004).

Oppenlander, T., Photochemical purification of water and air, WILEY-VCH Inc, (2003), Germany. 
Paxeus, N.. (2000). Organic compounds in municipal landfill leachate, Wat, Sci, Tech., 42, 323-333.

Tatsi, A. A., Zoubolis, A. I., Matis, K. A.. (2003). Coagulation-flocculation pre-treatment of sanitary landfill leachate, Chemosphere, 53, 737-744.

US Environmental Protection Agency (EPA), Municipal Solid Waste in the United States: 2000 Facts and Figures, Office of Solid Waste and Emergency Response, Washington DC, 2002 (EPA 530-R-02-001).

Wu, J. J., Wu, C. C., Ma, H. W., Chang, C. C.. (2004). Treatment of landfill leachate by ozone-based advanced oxidation process, Chemosphere, 54, 997-1003.

Zamora RM,Moreno A, Orta de Velasquez M, Ramirez I.. (2000). Treatment of landfill leachates by comparing advanced oxidation and coagulation-flocculation processes coupled with activated carbon adsorption. Water Sci Technol, 41, 231-235.

Table 1. Central composite design (CCD) in natural and coded variables with the experimental data and predicted values

\begin{tabular}{ccccccc}
\multicolumn{2}{c}{ Natural variable } & \multicolumn{3}{c}{ Coded variable } & \multicolumn{3}{c}{ Responses } \\
\hline$\xi_{1}$ & $\xi_{2}$ & Dosage & $\mathrm{pH}$ & COD & apparent color & Turbidity \\
\hline 8 & 10 & -1 & -1 & 8.1 & -24.3 & -51.4 \\
10 & 10 & 1 & -1 & 10.4 & 25.2 & -103.7 \\
8 & 12 & -1 & 1 & 16.6 & 33.8 & -5 \\
10 & 12 & 1 & 1 & 21.2 & 44.7 & 31.2 \\
7.59 & 11 & -1.41 & 0 & 15.2 & 32.6 & 9.2 \\
10.41 & 11 & 1.41 & 0 & 20 & 32.1 & -1.7 \\
9 & 9.59 & 0 & -1.41 & 9 & -30 & -131.7 \\
9 & 12.41 & 0 & 1.41 & 21.4 & 39.6 & 6.7 \\
9 & 11 & 0 & 0 & 18.5 & 32.1 & 1.7 \\
9 & 11 & 0 & 0 & 18.9 & 32.3 & 2.5 \\
9 & 11 & 0 & 0 & 16.8 & 32 & 5.9 \\
9 & 11 & 0 & 0 & 16.5 & 30.8 & 3.4 \\
9 & 11 & 0 & 0 & 17.7 & 29.5 & 3.4 \\
\hline
\end{tabular}


Table 2. Analysis of variance (ANOVA) for COD, apparent color and turbidity reductions

\begin{tabular}{lccccc}
\hline a-COD reduction & \multicolumn{1}{c}{} \\
\hline \multicolumn{1}{c}{ Source } & Sum of Squares & DF & Mean Square & F-Value & P-value \\
\hline Model & 218.47 & 5 & 43.69 & 19.7 & 0.0005 \\
Dosage & 23.42 & 1 & 23.42 & 10.56 & 0.0141 \\
pH & 169.61 & 1 & 169.61 & 76.45 & $<0.0001$ \\
Dosage $\times$ Dosage & 2.68 & 1 & 2.68 & 1.21 & 0.31077 \\
pH $\times$ pH & 23.07 & 1 & 23.07 & 10.4 & 0.0146 \\
Dosage $\times \mathrm{pH}$ & 1.32 & 1 & 1.32 & 0.6 & 0.4653 \\
Residual & 15.53 & 7 & 2.22 & & \\
Total & 234 & 12 & & & \\
\hline
\end{tabular}

b-Apparent color removal

\begin{tabular}{lccccc}
\hline Model & 5902.73 & 5 & 1180.55 & 15.60 & 0.0011 \\
Dosage & 445.41 & 1 & 445.41 & 5.88 & 0.0457 \\
$\mathrm{pH}$ & 3873.29 & 1 & 3873.29 & 51.17 & 0.0002 \\
Dosage $\times$ Dosage & 4.72 & 1 & 4.72 & 0.06 & 0.8100 \\
$\mathrm{pH} \times \mathrm{pH}$ & 1166.85 & 1 & 1166.85 & 15.42 & 0.0057 \\
Dosage $\times \mathrm{pH}$ & 372.49 & 1 & 372.49 & 4.92 & 0.0620 \\
Residual & 529.86 & 7 & 75.69 & & \\
Total & 12 & & & & \\
\hline
\end{tabular}

c-Turbidity reduction

\begin{tabular}{lccccc}
\hline Model & 27834.6 & 5 & 5566.93 & 745.53 & $<0.0001$ \\
Dosage & 124.15 & 1 & 124.15 & 16.63 & 0.0047 \\
$\mathrm{pH}$ & 17768.7 & 1 & 17768.7 & 2379.6 & $<0.0001$ \\
Dosage $\times$ Dosage & 1.94 & 1 & 1.94 & 0.26 & 0.6263 \\
$\mathrm{pH} \times \mathrm{pH}$ & 7878.2 & 1 & 7878.2 & 1055.06 & $<0.0001$ \\
Dosage $\times \mathrm{pH}$ & 1958.06 & 1 & 1958.06 & 262.23 & $<0.0001$ \\
Residual & 52.27 & 7 & 7.47 & & \\
Total & 27886.9 & 12 & & & \\
\hline
\end{tabular}



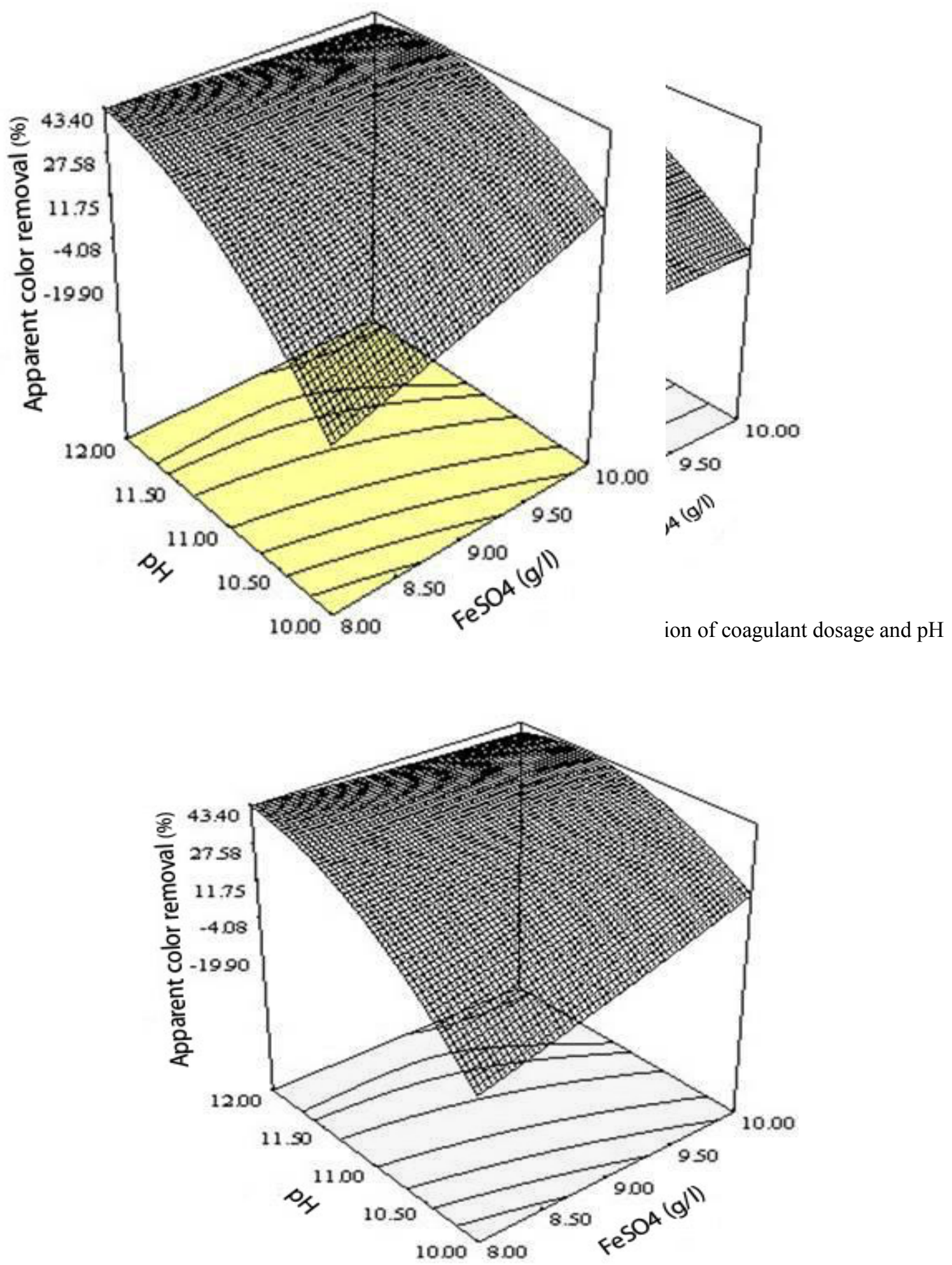

Figure 2. Three-dimensional response surface for apparent color removal as a function of coagulant dosage and $\mathrm{pH}$ 


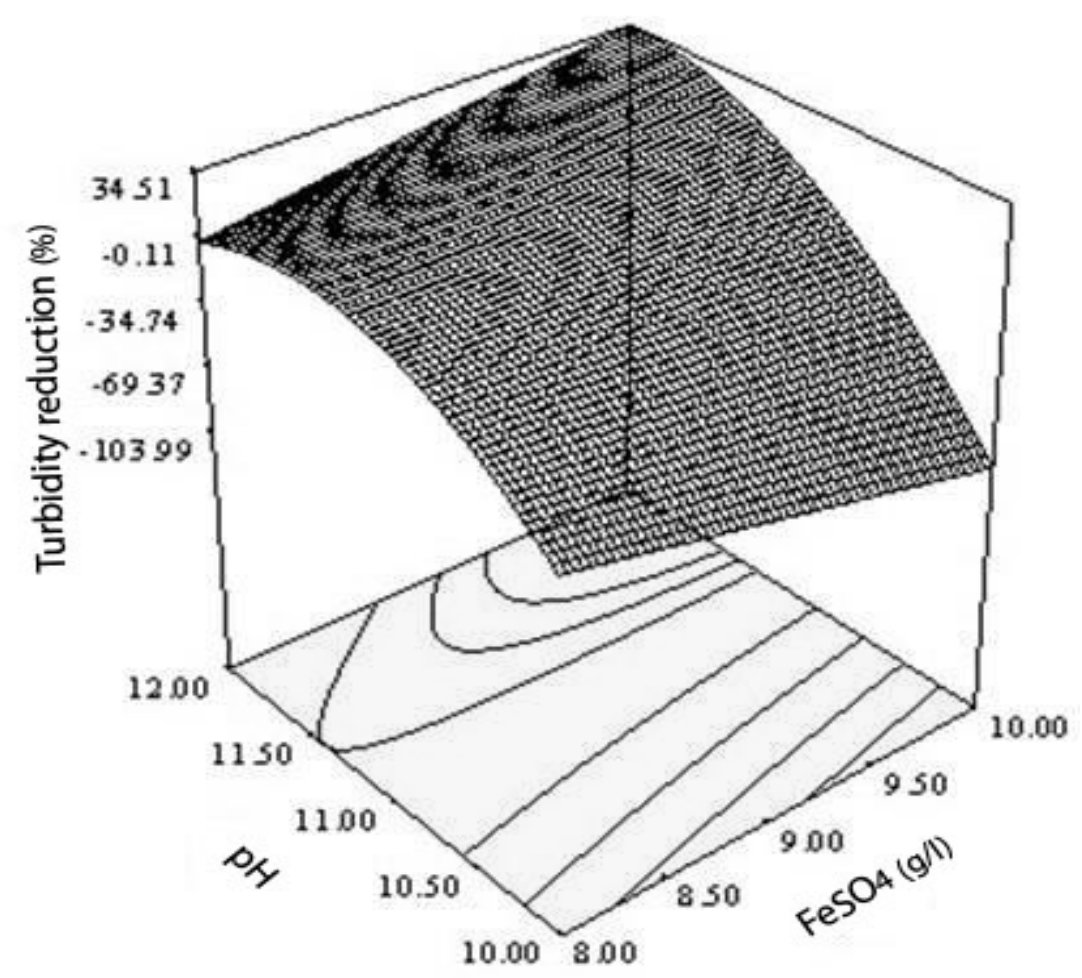

Figure 3. Three-dimensional response surface for turbidity reduction as a function of coagulant dosage and $\mathrm{pH}$

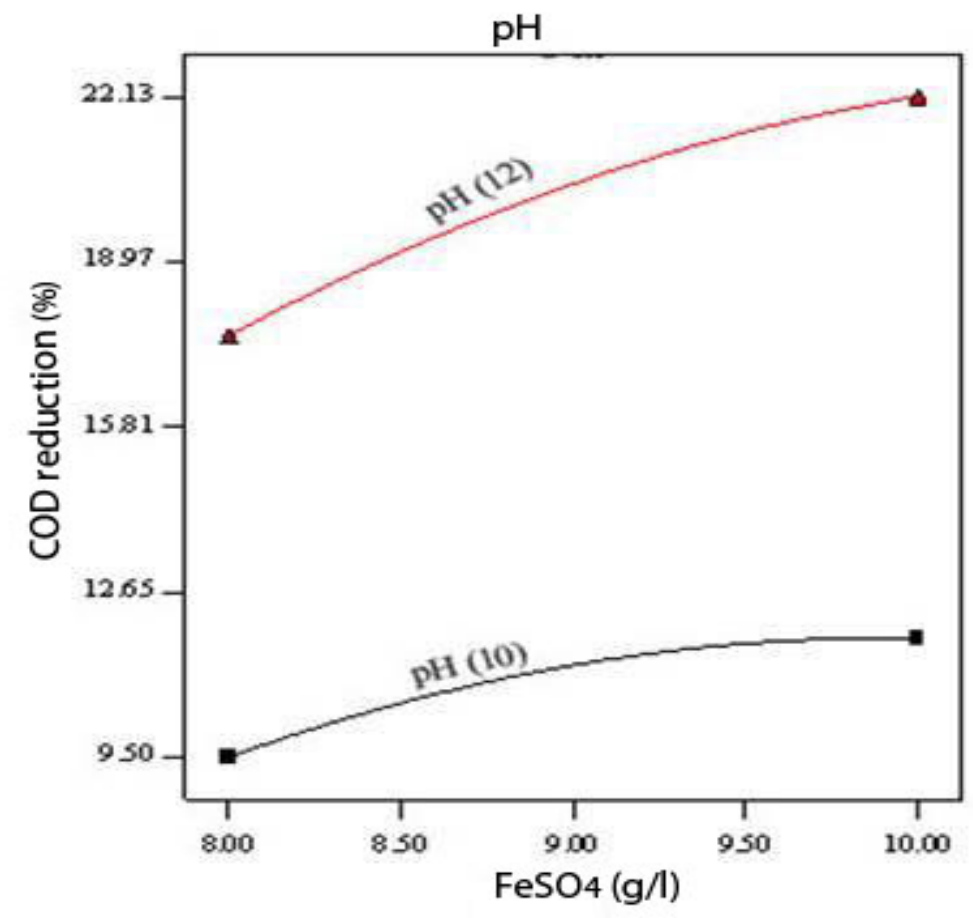

Figure 4. Interaction effect between coagulant dosage and $\mathrm{pH}$ on COD 


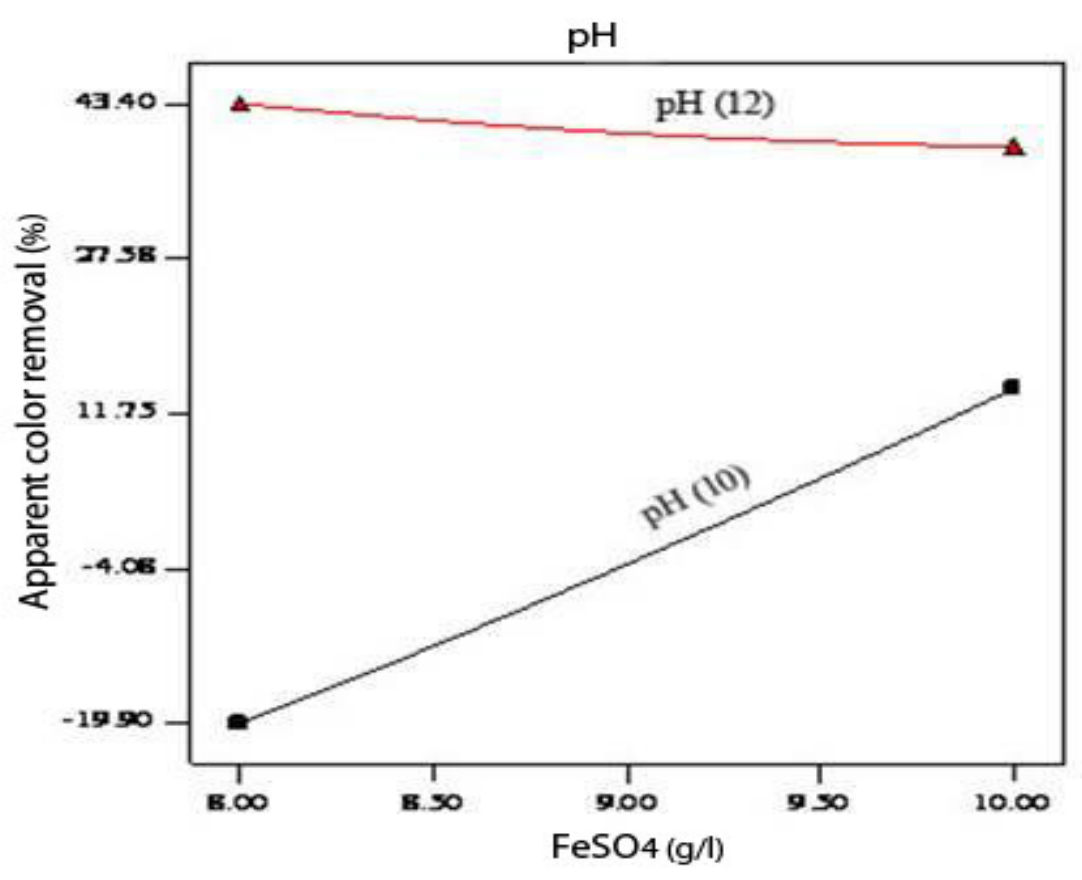

Figure 5. Interaction effect between coagulant dosage and $\mathrm{pH}$ on apparent color

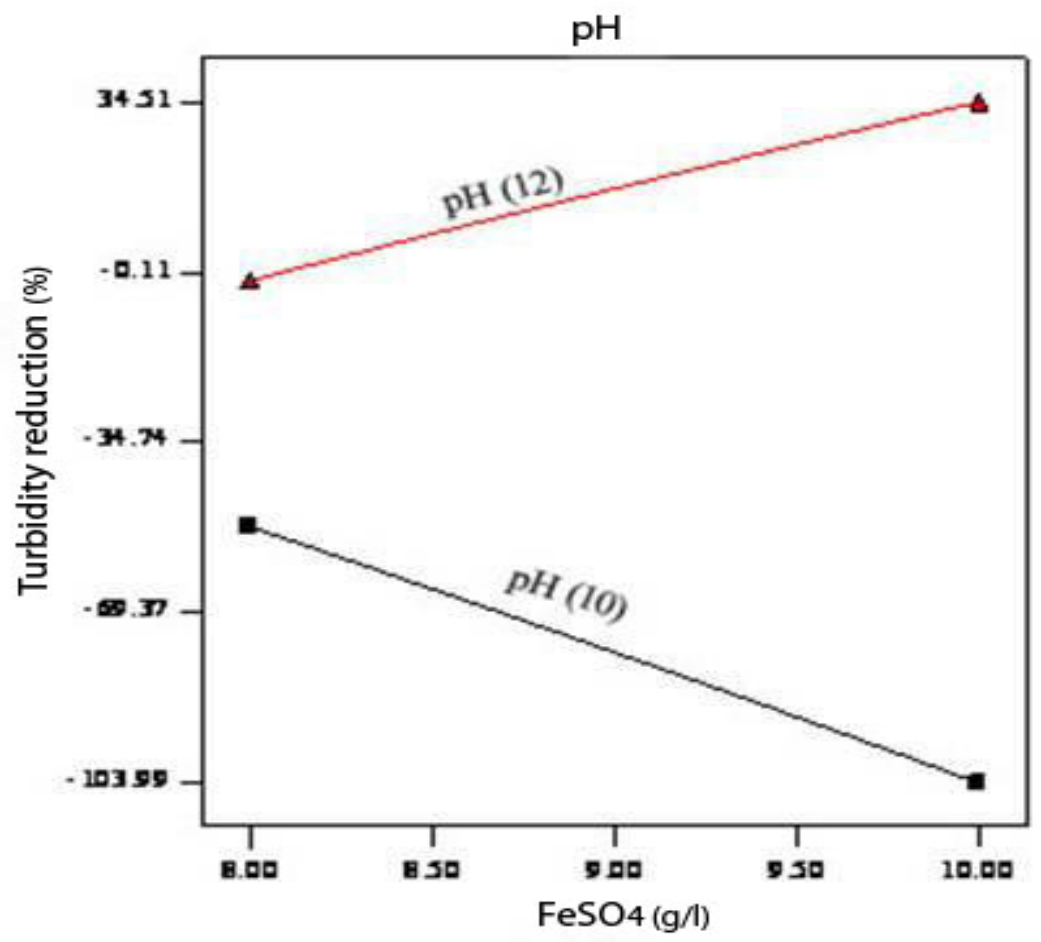

Figure 6. Interaction effect between coagulant dosage and $\mathrm{pH}$ on turbidity 